\title{
International Journal of Engineering
}

Journal Homepage: ww w. ije.ir

\section{Earthquake Prediction Modeling using Dynamic Changes Case Study: Alborz Region}

\author{
T. Sadeghian*, M. Emamgholi Babadi \\ Department of Civil Engineering, Faculty of Engineering and technology, Shahid Ashrafi Isfahani University, Isfahan, Iran
}

\section{$P A P E R \quad I N F O$}

Paper history:

Received 03 November 2020

Received in revised form 28 December 2020

Accepted 28 December 2020

\section{Keywords:}

Coulomb Stress

Dynamic Changes

Earth Viscosity

Earthquake Prediction

Rudbar Earthquake

\author{
$A B S S T R A C T$
}

This study aims to investigate the computational effect of Earth's viscosity on the Coulomb stress changes. Therefore, several large earthquakes in the Alborz region are selected and Coulomb stress changes are calculated in them, then the Coulomb stress temporal changes are shown by assuming the earth as an elastic layer on a viscous- elastic half-space. The spatial and temporal changes of the crustal deformation process associated with earthquakes depend on several parameters including the thickness of the lithosphere, viscosity of the asthenosphere, and dip angle of fault. The findings of this study are presented by determining the impact of modeling results on each of the input parameters through the sensitivity analysis of co-seismic and post-seismic deformation due to the dip-slip and strike-slip faulting. In addition to the useful results reported for the impact of parameters, the obtained results indicate the occurrence of numerous aftershocks in a region with increased Coulomb stress from 0.1 to $0.8 \mathrm{bar}$ and the non-occurrence or low-occurrence of aftershocks in a region with reduced Coulomb stress. In addition to the predicted locations of aftershocks, it is also possible to determine the location of the next major earthquake using Coulomb stress change calculations.

doi: $10.5829 /$ ije.2021.34.02b.07

\section{INTRODUCTION}

Crustal deformation measurement by modern methods has an important impact on current tectonic studies. Even though these measurements provide valuable information about the way of current earth deformation for researchers, they have no answer for the causes of these deformations. Furthermore, these measurements cannot determine and justify the future or past tectonic earth behavior [1]. Therefore, different branches of earth sciences apply the mathematics and physics-based models. In crustal deformation studies, the fault models based on the geological, geodetic and seismic information provide valuable information about the properties and behavior of a fault during the time. Based on the previous observations, the models provide estimates of future deformations and seismic risks for researchers and are so valuable for neighboring big cities of active seismic zones [2]. For example, some studies have been done using an artificial neural networks (ANN) [3] or a machine learning [4].
Crustal deformation occurs locally at long-term intervals (Quaternary and Miocene) due to the earthquakes and landslides in major fault systems. Considering this fact, the collision boundary of Arabian and Eurasian planes are expanded in a large zone (almost within the political borders of Iran) and it is in fact like a soft wide boundary between two moving and colliding Arabian and Eurasian planes. Deformation resulting from this collision is distributed in a wide range of different faulting systems in Iran.

This study seeks to indicate the computational impact of Earth's viscosity on Coulomb stress changes. Thus, several large earthquakes in the Alborz zone are selected and their Coulomb stress changes are calculated. The Coulomb stress changes are shown assuming the earth as an elastic layer on a viscouselastic half-space.

Modeling makes the temporal prediction of earthquakes possible. By modeling the Coulomb stress dynamic changes, the fault movements can be typically stimulated by the movement of tectonic plates and the

*Corresponding Author Email: tadbirtara@gmail.com (T. Sadeghian)

Please cite this article as: T. Sadeghian, M. Emamgholi Babadi, Earthquake Prediction Modeling using Dynamic Changes Case Study: Alborz Region, International Journal of Engineering, B: Applications Vol. 34, No. 02, (2021) 355-366 
position parameters on these planes in target periods. Different points on the planes, typically around the fault and created coverage networks around it are modeled by changes in the horizontal and vertical positions. These points are simulated at defined time intervals. The displacement of points over time can be investigated and expanded through these tools and models.

The research on the 1999 Marmara Earthquake Sequence in Turkey and the effects of Coulomb stress on it can be considered as the studies in this regard [5, $6]$ or also the first research on San Andreas Fault and the static stress changes [7]. Furthermore, research was done by Freed and Lin [8] on the Viscoelastic Stress Transfer over time in the 1999 Hector Mine Earthquake. Another study in this regard was conducted by Wang in 2008 on delay and triggering of an earthquake by a dynamic interaction between faults in the Xianshuihe fault zone in southwest China [9]. Paolucci et al. [10] also used a physics-based numerical approach to a model of earthquake ground motion due to induced seismicity in the Groningen gas field.

\section{PROBLEM STATEMENT}

2. 1. A Three-dimensional Semi-analytical Viscoelastic Model for Temporal Analysis of Earthquake Cycles The earthquake cycle analysis for large complex tectonic boundaries, which are deformed during thousands of years, needs the development of effective and complex models. In this study, Maxwell three-dimensional linear elastic semianalytical model is introduced and developed for utilizing the computational benefits of convolution theory in Fourier Theorem [11]. (According to convolution theory, the convolutive integrals can be solved by Fourier integral method). The new aspect of this model is the analytical solution for surface loading of an elastic plane on a viscoelastic half-space. When the model is fully implemented, the following cases will be simulated [12]

1. Inter-seismic stress accumulation in the upper locked section of the fault

2. Repeated earthquakes in pre-existing fault planes

3. The response of elastic viscosity under-plane asthenosphere after rupture.

According to the proposed approach, it is possible to investigate the thousand years of earthquake cycle along with the fault systems with complex three-dimensional geometry.

The long-term tectonic loading, sudden fault rupture and post-seismic transient return are among the key factors of the earthquake cycle and represent the important spatial and temporal characteristics of crustal deformation. Understanding these dynamics for complex continental borders needs temporal three- dimensional models that can simulate deformation at the large scale of time and space. These models should include both the real three-dimensional geometry of fault systems and the viscoelastic response of repeated earthquakes [13]. Even by limiting the quasi-static mode (no seismic waves), these models should include the time period from rupture (about 100 seconds) to return which takes about 1000 years as well as the longitudinal range from the fault thickness (about $500 \mathrm{~m}$ ) to deformation boundary (about $1000 \mathrm{~km}$ ) [14].

The pure numerical algorithms, which even can be run in the most powerful computers, cannot sufficiently solve this wide range of length and time. Therefore, there is a need for improved analytical methods to reduce the numerical range of issues.

This study provides a semi-analytical solution for the response of an elastic plane overlying a viscoelastic half-space due to the time-dependent volumetric point forces (Figure 1). Although the presented method expands an analytical method [15], it has the computational advantages compared to the numerical methods and has a qualitative agreement with most of the numerical pure studies. The three-dimensional issue is analytically solved both in vertical $(\mathrm{z})$ and time $(\mathrm{t})$ dimensions. While, a solution is expanded in two horizontal dimensions $(\mathrm{x}, \mathrm{y})$ in Fourier Transform space to utilize the advantages of convolution theory. Using this method, the fault horizontal pattern and distribution of slip can be without an increase in complex computational load. The three-dimensional model shown here can be easily run in a computer through a network that covers a spatial zone from $1 \mathrm{~km}$ to 2048 $\mathrm{km}$; this model can also be implemented for broader networks.

The viscoelastic half-space has the viscosity coefficient of $\eta \cdot d_{1}$ and $d_{2}$ are the low and high locking depth, respectively. The velocity vectors are applied in opposite directions to the fault plane.

Here, the semi-analytical solution to the threedimensional viscoelastic issue is expanded for the vertical strike-slip fault model and it compares the

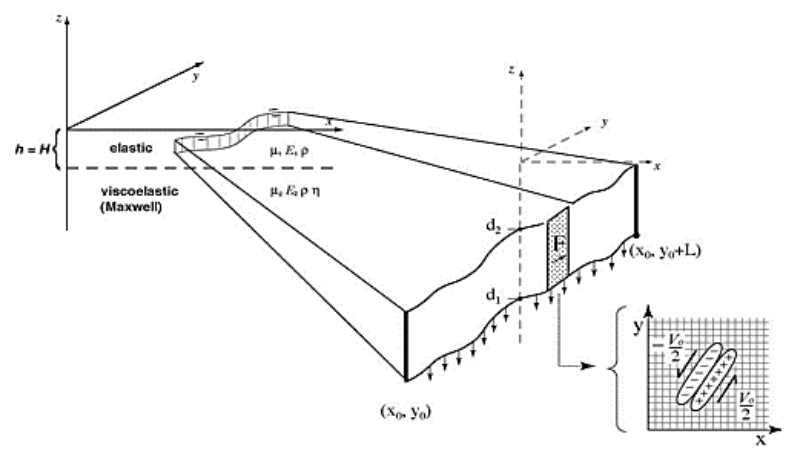

Figure 1. Three-dimensional fault Fourier model which simulates an elastic layer on a viscoelastic linear half-space. 
numerical results compared to the known analytical solutions to assess the accuracy and efficiency of the technique. These models are necessary because the seismic and geodetic measurements only record a small part of the earthquake cycle on the main parts of the fault, thus the viscoelastic asthenosphere response which involves a long-term fault-fault connection remains with a weak bound. Furthermore, the mechanical post-seismic deformations leave numerous unanswered questions that are associated with the rheological parameters and ground time-dependent relaxation process.

Several post-seismic models have been developed with adaption to the surface geodetic velocities. These models include the poroelastic flow of fluids in the upper crust, deep aftershocks and fault zone collapse. However, numerous efforts are taken to investigate these models from the post-seismic behavior. A model based on the viscoelastic connection between the upper elastic plane and a viscoelastic linear half-space is investigated in this study $[16,17]$.

Furthermore, the effect of gravity is considered in a viscoelastic model to ensure the results of vertical strikes.

In addition to understanding the post-seismic deformation, numerous studies have focused on the three-dimensional development of the stress field. Coulomb stress changes caused by major earthquakes are utilized to explain the triggering of subsequent earthquakes and aftershocks [18-20].

Several stress transfer calculations are only based on the pure elastic models because the analytical solutions Okada [21] can be effectively measured in three dimensions for actual geometry of fault and rupture history. However, the viscoelastic models are needed to investigate the temporal deformation and earthquake triggering at the time scales comparable with return periods. As a result, several models of actual elasticity are developed and applied for stress triggering after major earthquakes.

However, due to the limitations in computer speed and memory, most of these numerical models are limited with a relatively simple return interval and fault geometry. Therefore, the current models do not sufficiently show the three-dimensional interaction of multiple fault intersection branches covering several earthquake cycles. A complete model is combined from two concepts which can improve the seismic hazard analyses and provide a better understanding of the physics of the earthquake cycle [22].

\section{2. Coulomb Stress}

Coulomb stress is a criterion of shear stress loading on a fault with a particular azimuth. Positive Coulomb stress indicates the tendency towards the fault plane rupture and the negative stress indicates the non-tendency towards the fault plane rupture. This thesis uses the method by King et al. [7] and defined the Coulomb rupture criterion as follows:

$\sigma_{f}=\tau-\mu_{f} \sigma_{n}$

In this regard, $\sigma_{n}$ and $\tau$ are normal and shear stresses on the rupture plane respectively and $\mu_{f}$ is the effective coefficient of friction. The model used in this study produces the three-dimensional displacement field vector from which the stress tensor is calculated. The shear stress and tension are assumed right-handed and positive because Coulomb stress is zero at the surface and becomes singular in locking depth. Coulomb stress is calculated at half locking depth and $\mu_{f}$ is assumed equal to 0.6. The main objective is to detect Coulomb stress accumulation both before and after the earthquake.

\section{3. Coulomb Stress Change Modelling} perform the calculations, a variety of parameters especially the parameters describing the reference fault (the fault model which is built by optimal input geometric and physical parameters and based on which the faults are compared) and receiver fault are introduced into the model. Reference fault is determined with rupture parameters (slip, depth, length and Rake angle) and fault geometry (strike and dip angles). The receiver plane of fault, on which the Coulomb stress change is determined, is described by geometry and mechanism of faulting (strike, dip and Rake angles) [23].

Furthermore, the friction coefficient of the receiver fault and the half-space elastic parameters should be determined. The friction coefficient is determined from 0.6 to 0.8 using the experimental samples, but it seems that it is possible to change it at the interval from zero to 0.8 in stress triggering studies. The calculated results show a high sensitivity to the friction coefficient. In performing the calculations, the coefficient of friction is selected equal to 0.6. Therefore, Poisson's ratio is selected equal to $0.25,8 \times 10^{5} \mathrm{bar}$ for Young's modulus and $3.3 \times 10^{10}$ Pascal for shear modulus [24].

Rupture parameters are the empirical parameters that connect the rupture length, width and average to the intensity of earthquakes.

\section{REFERENCE MODEL}

According to Figure 2 for the thickness of the elastic layer, the reference value of $41 \mathrm{~km}$ is used in this regard. Fault plane dip angle is selected equal to 20 degrees and locking depth above the rupture plane equal to $6 \mathrm{~km}$. 
Furthermore, according to Table 1, the rupture plane is considered as the dip and strike-slip rate with a slip of 5 $\mathrm{m}$ and an area of $40 \times 80$ square kilometers. Dimensions in Figure 2 are selected according to the similar geometric values in previous studies $[25,26]$.
In addition to the geometry and location of reference faulting, the physical environment of the upper elastic layer should be described with other values. For these parameters, the average international values are selected according to Table 2 .

TABLE 1. Geometry of reference faults considers the Coulomb stress changes modeling due to an earthquake.

\begin{tabular}{|c|c|c|c|c|c|c|c|}
\hline \multirow{2}{*}{ Fault } & \multirow{2}{*}{ Length (km) } & \multirow{2}{*}{ Width (km) } & \multirow{2}{*}{ Locking depth (km) } & \multirow{2}{*}{ Dip (deg.) } & \multirow{2}{*}{ Rake angle (deg.) } & \multicolumn{2}{|c|}{ Slip } \\
\hline & & & & & & Strike & Dip \\
\hline Reference Fault 1 & 80 & 40 & 6.0 & 20.0 & 0.0 & 5.0 & 5.0 \\
\hline Reference Fault 2 & 80 & 40 & 6.0 & 20.0 & 90.0 & 5.0 & 5.0 \\
\hline
\end{tabular}

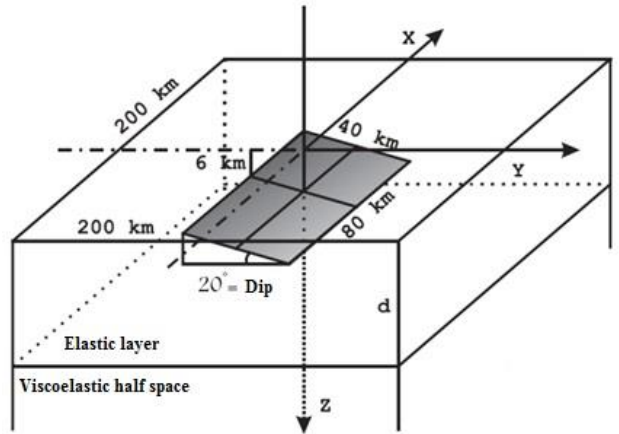

Figure 2. The geometry of fault and reference environment used in modeling the sensitivity analysis

The applied half-space utilizes an elastic layer with a thickness of $41 \mathrm{~km}$ and a viscoelastic half-space. The coordinate system origin is at the top of the fault plane center and its $\mathrm{x}$-axis is parallel to the longitudinal direction of the fault plane. The upper reference fault plane limit is at a depth of about $6 \mathrm{~km}$ from the ground. The fault plane is $80 \mathrm{~km}$ in length and $40 \mathrm{~km}$ in width and has a dip angle of 20 degrees to the horizontal level.

\section{DATA ANALYSIS}

4. 1. Rupture Parameters The data of earthquake $\mathrm{Mw}=7.4$ (20.6.1990) in the Rudbar area was used for doing the calculations. Characteristics of this earthquake are extracted from the CMT catalog which gives us information such as the depth and magnitude of earthquakes as well as the spatial and temporal information.

TABLE 2. Physical properties of the elastic layer

\begin{tabular}{ccccc}
\hline $\begin{array}{c}\text { Depth } \\
(\mathbf{k m})\end{array}$ & $\begin{array}{c}\text { Wave } \\
\text { velocity, } \\
\mathbf{P},(\mathbf{k m} / \mathbf{s})\end{array}$ & $\begin{array}{c}\text { Wave } \\
\text { velocity, } \\
\mathbf{S},(\mathbf{k m} / \mathbf{s})\end{array}$ & $\begin{array}{c}\text { Density } \\
\left(\mathbf{k g} / \mathbf{m}^{3}\right)\end{array}$ & Viscosity (Pa.s) \\
\hline 41 & 6.7 & 3.87 & 2900 & 0.0 \\
\hline
\end{tabular}

\section{2. Dynamic Modelling of Coulomb Stress} Changes in the Alborz Mountains It is essential to know about the time and place of the severe earthquake and possible aftershocks due to the alarm before the earthquake and aftershocks to reduce the financial and human losses. Therefore, this question should be answered how the occurrence of an earthquake can cause another earthquake? This fact should be taken into account that an earthquake is along with faulting or rupture in the elastic crust of Earth. Therefore, the rupture criterion should be investigated in the elastic crust of Earth (Coulomb rupture criterion). According to the Coulomb rupture criterion, the tendency of rock to the elastic rupture is subject to normal and shear stresses imposed to the assumed rupture plane, and if the rate of Coulomb stress is higher than the critical limit, the elastic rupture or earthquakes will occur. Thus, the time-dependent modeling of Coulomb stress changes in the earth's crust caused by the tectonic co-seismic, post-seismic and pre-seismic activities, can be used as a criterion for estimating the time and place of earthquake hazard. This research

Wells Experimental relations provide the slip rate; and we obtain the direction of fault movement, which is the boundary condition in this section, through the Focal mechanism for a strike-slip fault, for instance, the lefthanded Strike-Slip.

The experimental relations [27] between the intensity of earthquake and rupture parameters are utilized to calculate the length and width of rupture as well as the detachment due to the earthquake as follows.

$$
\begin{aligned}
& \log (R L D)=-2.44+0.59 \times M_{w} \\
& \log (R W)=-1.01+0.32 \times M_{w} \\
& \log (A D)=-4.80+0.69 \times M_{w}
\end{aligned}
$$

In the above equations, $M w$ is the earthquake moment rate, RLD is the subsurface rupture length in kilometer, RW is the width of rupture along the fault dip in kilometer and $A D$ is the average rupture in meter. 
4. 3. Three-dimensional Modelling of Displacement Field and Coulomb Stress Changes The model introduced by Okada [28] is utilized for modeling the three-dimensional displacement field of this earthquake, the results of the calculation are shown in Figures 3 and 4.

\section{4. Investigating Coulomb Stress Time Changes} for Selected Earthquakes Afterward, Coulomb stress changes are measured for nine major mechanical and historical earthquakes with magnitudes greater than 6 in the Alborz region at the intervals of 5 years assuming the strike and dip slip receiver faults (the faults in these regions are more from these two types). The characteristics of selected earthquakes are presented in Table 3. Figure 4 to Figure 7 show the Coulomb stress time changes at intervals of 5 years assuming the strike-slip receiver faults. Figure 8 to Figure 11 shows the Coulomb stress time changes at intervals of 5 years assuming the dip-slip receiver faults. Coulomb stress

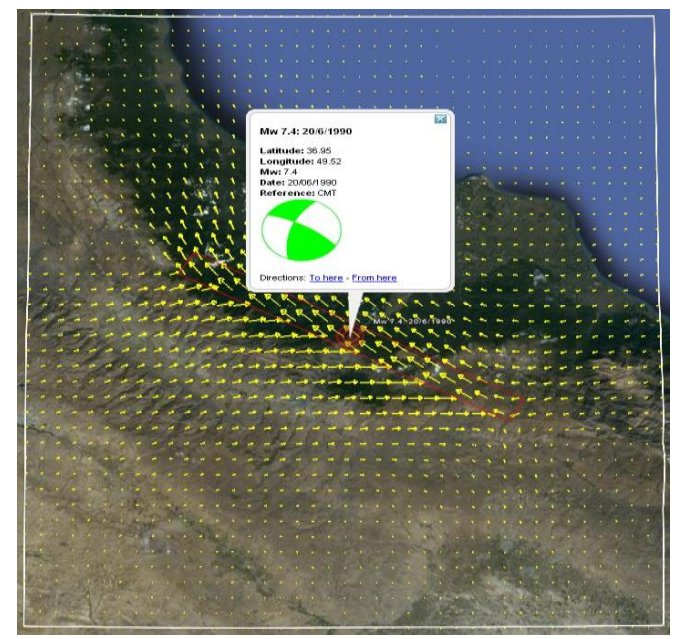

Figure 3. Horizontal displacement model due to the earthquake of Mw = 7.4 (20.6.1990) in Rudbar area in meter time changes at intervals of 5 years can be seen in sequential forms.

For calculations, an elastic layer with a thickness of $41 \mathrm{~km}$ and a Lame coefficient of $40 \mathrm{GPa}$ on the viscoelastic half-space with a Lame coefficient of 70 GPa and a viscosity of $1.0 \times 10^{20}$ Pas. To achieve more accurate results, the fault planes are divided into smaller pieces. The results of calculations indicate the Coulomb stress changes at different time intervals affected by the viscosity of the viscoelastic half-space.

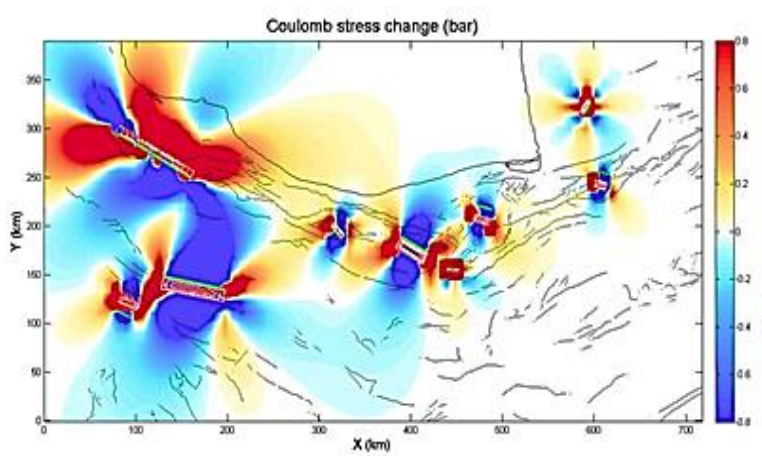

(a)

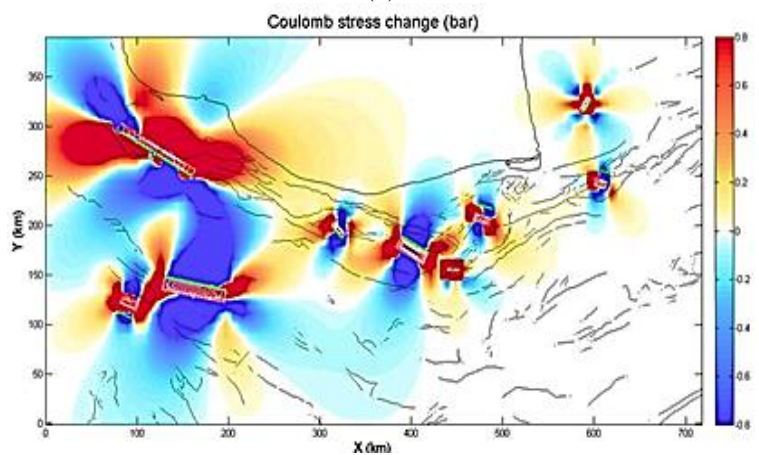

(b)

Figure 4. Coulomb stress time changes at 5-year time intervals assuming the Strike-slip receiver faults, a- Coulomb stress changes during an earthquake, b- Coulomb stress changes 5 years after the earthquake.

TABLE 3. Characteristics of selected earthquake for a dynamic study of Coulomb stress changes

\begin{tabular}{|c|c|c|c|c|c|c|c|c|}
\hline Faults name & rake & dip & strike & Mag. & Depth (km) & lon (deg) & lat (deg) & Date $(\mathrm{mm} / \mathrm{dd} / \mathrm{yyyy})$ \\
\hline North Alborz F. & 126 & 30 & 106 & Ms:6.3 & 12 & 53.32 & 36.36 & $4 / 11 / 1935$ \\
\hline North Alborz F. & 90 & 45 & 120 & Ms:6.8 & 13 & 52.47 & 36.07 & $7 / 2 / 1957$ \\
\hline Ipak F. & 70 & 52 & 101 & Ms:7.2 & 15 & 49.81 & 35.71 & $9 / 1 / 1962$ \\
\hline Khazar F. & 126 & 30 & 106 & Mw:6.1 & 15 & 54.77 & 36.68 & $10 / 29 / 1985$ \\
\hline North Alborz F. & 24 & 83 & 91 & Mw:6 & 30 & 52.97 & 35.9 & $1 / 20 / 1990$ \\
\hline Rudbar F. & 32 & 73 & 300 & Mw:7.4 & 18 & 49.35 & 36.99 & $6 / 20 / 1990$ \\
\hline Ipak F. & 99 & 29 & 295 & Mw:6.5 & 11 & 49.02 & 35.6 & $6 / 22 / 2002$ \\
\hline Kandevan F. & 98 & 67 & 319 & Ms:6.4 & 27 & 51.57 & 36.26 & $5 / 28 / 2004$ \\
\hline Khazar F. & -156 & 67 & 211 & ML:6.2 & 17 & 54.58 & 37.4 & $10 / 7 / 2004$ \\
\hline
\end{tabular}




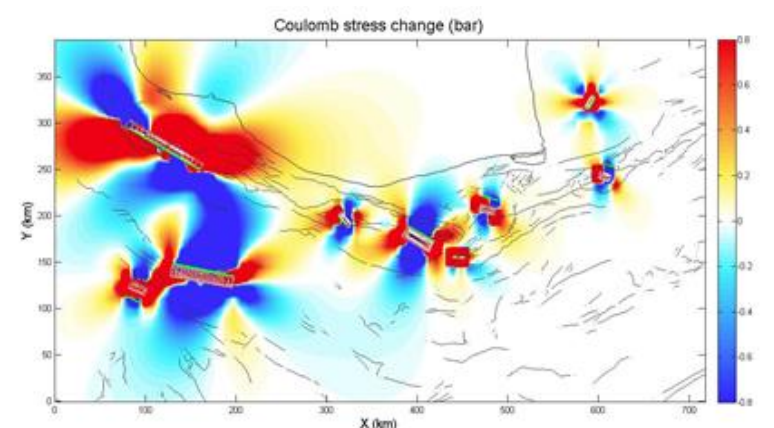

(a)

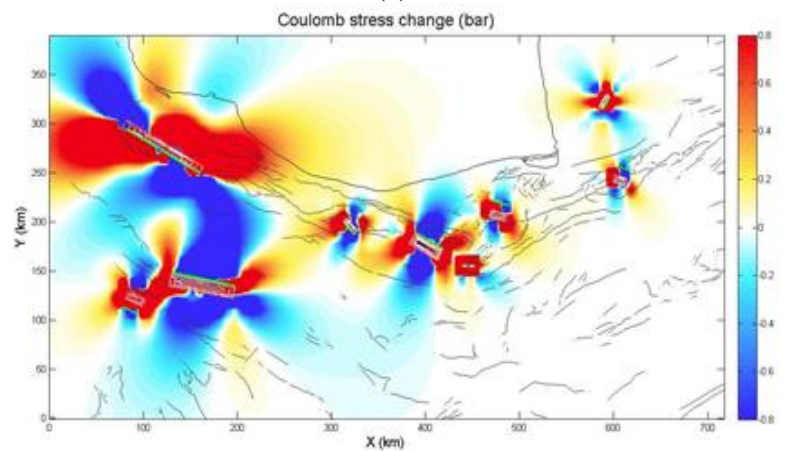

(b)

Figure 5. Coulomb stress changes at 5-year time intervals assuming the strike-slip receiver faults: a - Coulomb stress changes 10 years after the earthquake, b - Coulomb stress changes 15 years after the earthquake

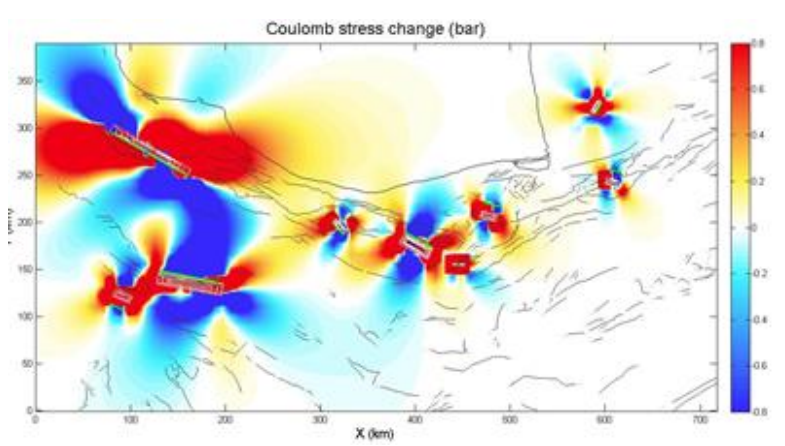

(a)

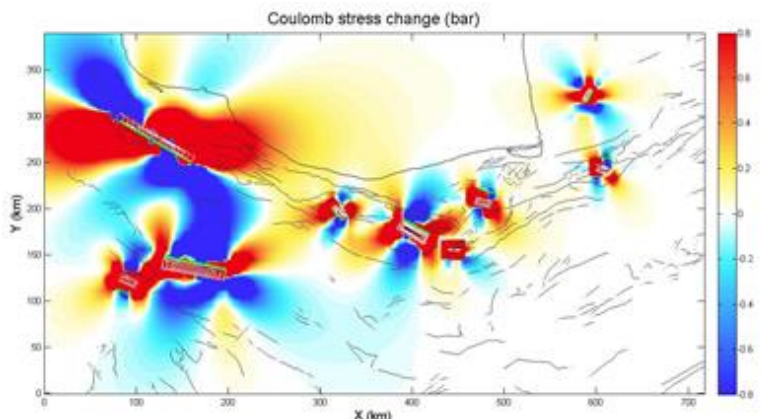

(b)

Figure 6. Coulomb stress changes at 5-year time intervals assuming the strike-slip receiver faults a - Coulomb stress changes 20 years after the earthquake, b - Coulomb stress changes 25 years after the earthquake

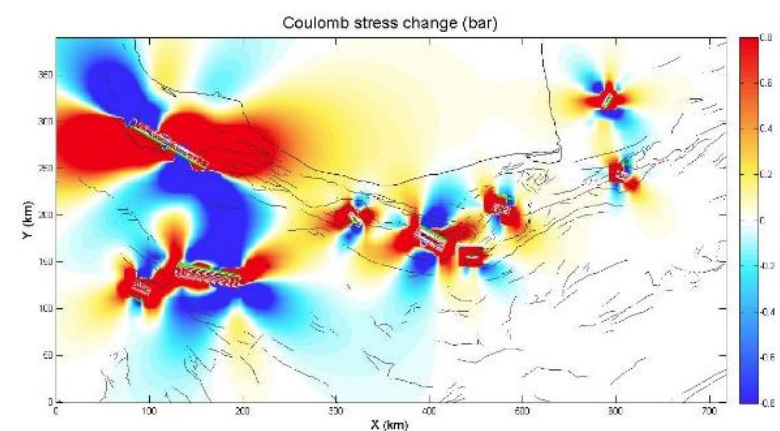

Figure 7. Coulomb stress changes at 5-year time intervals assuming the strike-slip receiver faults: Coulomb stress changes 30 years after the earthquake.

\section{5. Numerical Results of Dynamic Changes in Coulomb Stress of Rudbar Zone Assuming the Strike-Slip Fault The numerical value of the} dynamic range for Coulomb stress in the Rudbar zone is investigated according to Table 4 for strike-slip faults.

According to this assessment for strike-slip faults, the zones, which have had the increase and reduction in Coulomb stress over time, are identified and the numerical values of this increased Coulomb stress are determined in the North - North East - East - and West of Rudbar zone. Furthermore, they have had reduced

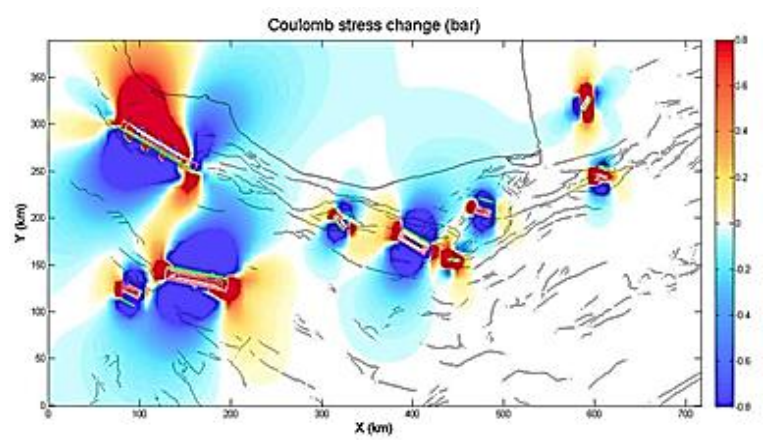

(a)

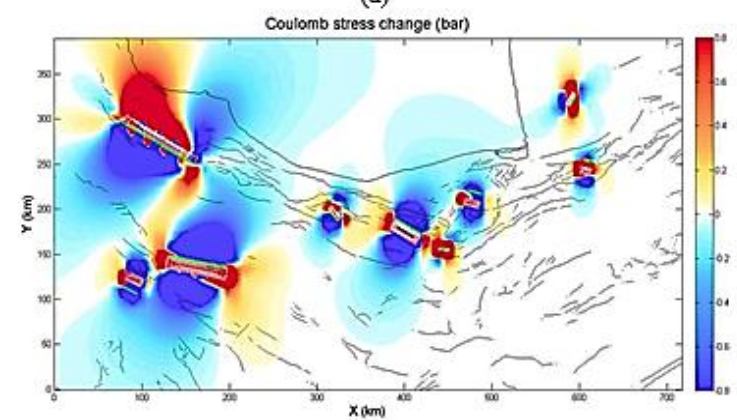

(b)

Figure 8. Coulomb stress changes at 5-year time intervals assuming the dip slip receiver faults; a - Coulomb stress changes during the earthquake, $\mathrm{b}$ - Coulomb stress changes 5 years after the earthquake 


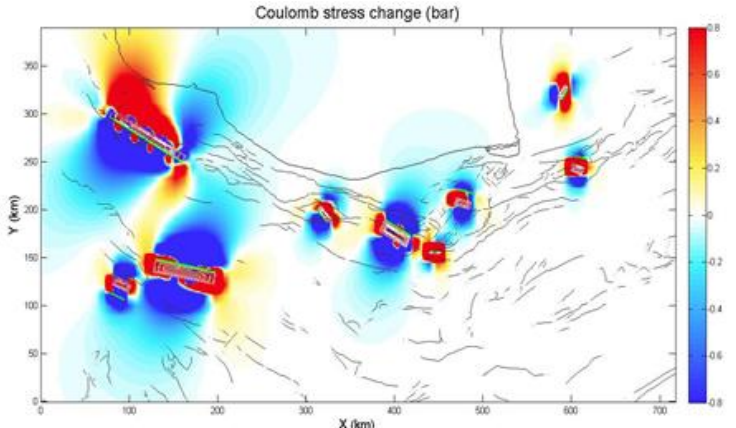

(a)

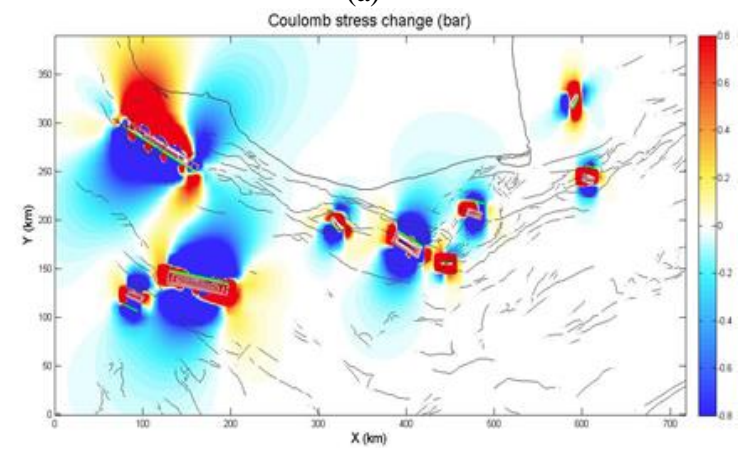

(b)

Figure 9. Coulomb stress changes at 5-year time intervals assuming the dip-slip receiver faults a - Coulomb stress changes 10 years after the earthquake, b - Coulomb stress changes 15 years after the earthquake

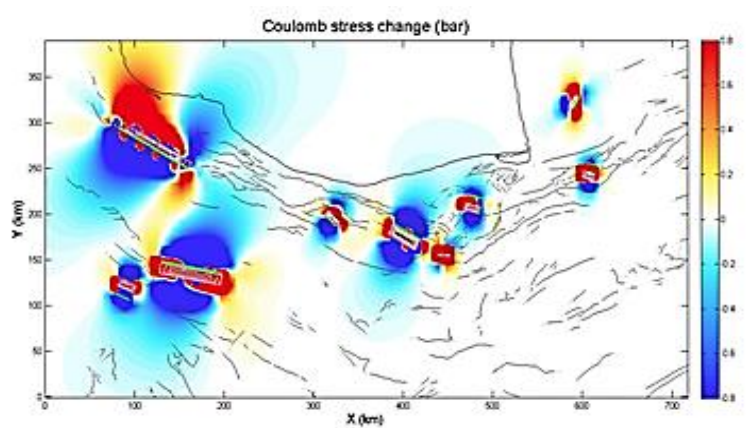

(a)

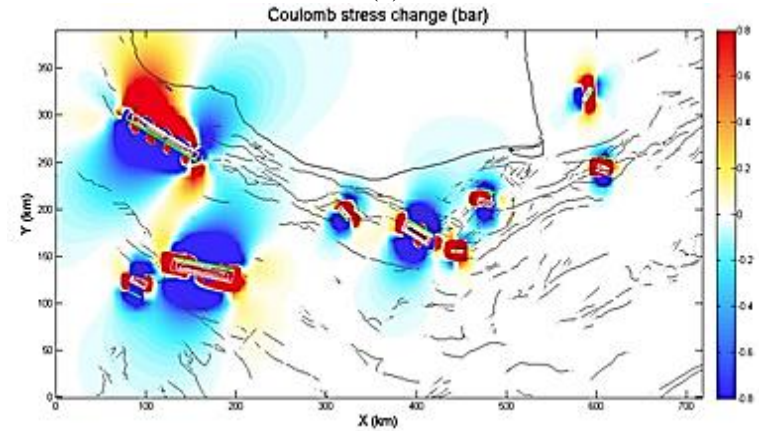

(b)

Figure 10. Coulomb stress changes at 5-year time intervals assuming the dip-slip receiver faults: a - Coulomb stress changes 20 years after the earthquake, b - Coulomb stress changes 25 years after the earthquake

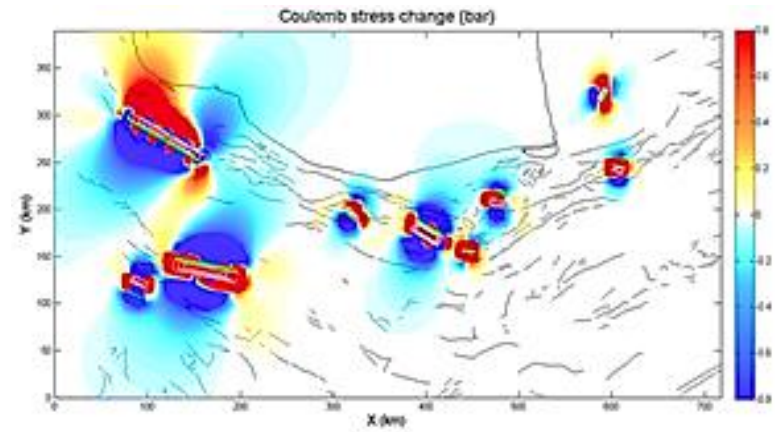

Figure 11. Coulomb stress changes at 5-year time intervals assuming the dip-slip receiver faults Coulomb stress changes 30 years after the earthquake

Coulomb stress in North West - South East - South and Southwest directions. According to Table 4, the farther from the center of the faulting plane zone (during a constant time), the more the Coulomb stress is reduced. Furthermore, this stress is also enhanced both in spatial and time dimensions by imposing the 5-year intervals in some directions and reduced in other dimensions. Furthermore, the rate of changes has been positive in the enhanced Coulomb stress zone and negative in the reduced Coulomb stress zone.

According to Figures 12 to 14 , it is observed that most of the aftershocks occurred in an increased Coulomb stress zone. According to the number and location of an earthquake that occurred in the 5-year intervals, it can be concluded that in zones with high Coulomb stress, the earthquakes and subsequent aftershocks have been increased. For instance, the center of earthquakes in the Rudbar zone increased the Coulomb stress zone in 1995.

As considered, the number of earthquakes that occurred in increased Coulomb stress in 2005 was greater than 1995 and 2000 and this indicates that the number and possibility of earthquakes in these regions has been higher over time and by increased Coulomb stress. Accordingly, this possibility can be higher for the regions with increased Coulomb stress during 2015 and 2020 .

\section{6. Numerical Results of Dynamic Changes in Coulomb Stress of Rudbar Zone Assuming the Dip-Slip Fault According to this assessment for} dip-slip faults, the zones, which have had the increase and reduction in Coulomb stress over time, are identified and the numerical values of this increased Coulomb stress on dip-slip faults are determined in the North - North West- and South East of Rudbar zone. Furthermore, they have had reduced Coulomb stress in North East - South- and Southwest directions. According to Tables 5-8, the farther from the center of the faulting plane zone (during a constant time), the more the Coulomb stress is reduced. Contrary to strike- 
TABLE 4. Numerical results of dynamic changes in Coulomb stress of Rudbar zone in 5-year intervals assuming

\begin{tabular}{|c|c|c|c|}
\hline Time & $\begin{array}{l}\text { Coulomb } \\
\text { stress }\end{array}$ & $\begin{array}{c}\text { Distance from } \\
\text { fault center }(\mathbf{k m})\end{array}$ & $\begin{array}{l}\text { Intervals of stress } \\
\text { levels in Bar }\end{array}$ \\
\hline \multirow{6}{*}{$\begin{array}{l}\text { During an } \\
\text { earthquake }\end{array}$} & \multirow{4}{*}{ Increase } & $0-50$ & $0.6-0.8$ \\
\hline & & $50-100$ & $0.4-0.6$ \\
\hline & & $100-200$ & $0-0.4$ \\
\hline & & $0-50$ & -0.6 \\
\hline & \multirow[t]{2}{*}{ Reduction } & $50-100$ & $(-0.4)-(-0.6)$ \\
\hline & & $100-200$ & $0-(-0.2)$ \\
\hline \multirow{6}{*}{5 years later } & \multirow{4}{*}{ Increase } & $0-75$ & $0.6-0.8$ \\
\hline & & $75-120$ & $0.4-0.6$ \\
\hline & & $120-280$ & $0-0.4$ \\
\hline & & $0-140$ & $(-0.6)-(-0.8)$ \\
\hline & \multirow[t]{2}{*}{ Reduction } & $140-180$ & $(-0.4)-(-0.6)$ \\
\hline & & $180-350$ & $0-(-0.4)$ \\
\hline \multirow{6}{*}{$\begin{array}{l}10 \text { years } \\
\text { later }\end{array}$} & \multirow{3}{*}{ Increase } & $0-100$ & $0.6-0.8$ \\
\hline & & $100-130$ & $0.4-0.6$ \\
\hline & & $130-300$ & $0-0.4$ \\
\hline & \multirow{3}{*}{ Reduction } & $0-150$ & $(-0.6)-(-0.8)$ \\
\hline & & $150-210$ & $(-0.4)-(-0.6)$ \\
\hline & & $210-350$ & $0-(-0.4)$ \\
\hline \multirow{6}{*}{$\begin{array}{l}15 \text { years } \\
\text { later }\end{array}$} & \multirow{3}{*}{ Increase } & $0-120$ & $0.6-0.8$ \\
\hline & & $120-200$ & $0.4-0.6$ \\
\hline & & $220-320$ & $0-0.4$ \\
\hline & \multirow{3}{*}{ Reduction } & $0-100$ & $(-0.6)-(-0.8)$ \\
\hline & & $100-150$ & $(-0.4)-(-0.6)$ \\
\hline & & $150-250$ & $0-(-0.4)$ \\
\hline \multirow{6}{*}{$\begin{array}{l}20 \text { years } \\
\text { later }\end{array}$} & \multirow{3}{*}{ Increase } & $0-130$ & $0.6-0.8$ \\
\hline & & $130-180$ & $0.4-0.6$ \\
\hline & & $180-390$ & $0-0.4$ \\
\hline & \multirow{3}{*}{ Reduction } & $0-80$ & $(-0.6)-(-0.8)$ \\
\hline & & $80-110$ & $(-0.4)-(-0.8)$ \\
\hline & & $100-110$ & $0-(-0.4)$ \\
\hline \multirow{6}{*}{$\begin{array}{l}25 \text { years } \\
\text { later }\end{array}$} & \multirow{3}{*}{ Increase } & $0-150$ & $0.6-0.8$ \\
\hline & & $150-200$ & $0.4-0.6$ \\
\hline & & $200-410$ & $0-0.4$ \\
\hline & \multirow{3}{*}{ Reduction } & $0-70$ & $(-0.6)-(-0.8)$ \\
\hline & & $70-100$ & $(-0.4)-(-0.6)$ \\
\hline & & $100-170$ & $0-(-0.4)$ \\
\hline \multirow{6}{*}{$\begin{array}{l}30 \text { years } \\
\text { later }\end{array}$} & \multirow{3}{*}{ Increase } & $0-160$ & $0.6-0.8$ \\
\hline & & $160-180$ & $0.4-0.6$ \\
\hline & & $180-430$ & $0-0.4$ \\
\hline & \multirow{3}{*}{ Reduction } & $0-60$ & $(-0.6)-(-0.8)$ \\
\hline & & $60-90$ & $(-0.4)-(-0.6)$ \\
\hline & & $90-150$ & $0-(-0.4)$ \\
\hline
\end{tabular}

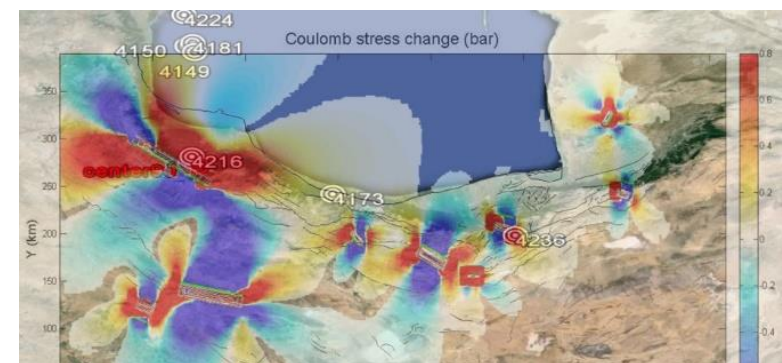

Figure 12. Earthquakes occurred in increased Coulomb stress zone in 1995

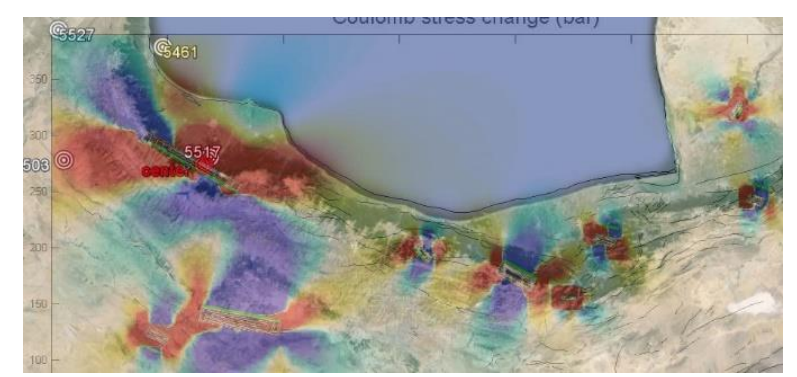

Figure 13. Earthquakes occurred in increased Coulomb stress zone in 2000

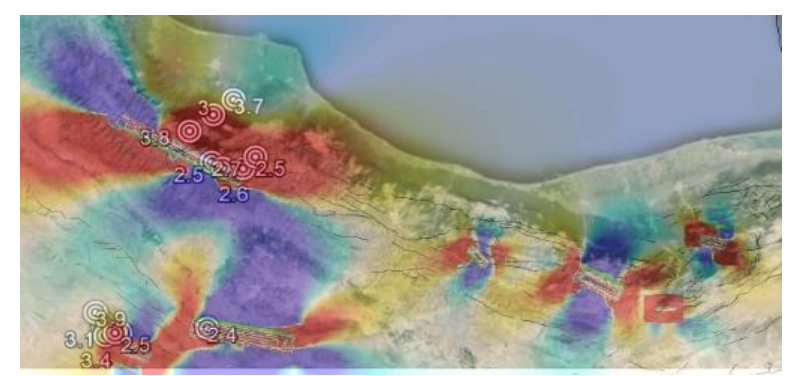

Figure 14. Earthquakes occurred in increased Coulomb stress zone in 2005

slip faulting, this stress is reduced both in spatial and time dimensions by imposing the 5-year intervals in some directions. Furthermore, the rate of changes has been negative-positive in the enhanced Coulomb stress zone and positive in the reduced Coulomb stress zone.

TABLE 5. Properties of earthquakes created in Central Alborz and Rudbar zones in 1995

\begin{tabular}{lccccc}
\hline Magnitude & Depth & Longitude & Latitude & $\begin{array}{c}\text { Occurrence } \\
\text { Time }\end{array}$ & Date \\
\hline 4.6 & 48 & 49.43 & 38.48 & $16: 54$ & $15 / 05 / 1995$ \\
4.4 & 33 & 49.33 & 38.56 & $21: 54$ & $15 / 05 / 1995$ \\
4.2 & 33 & 46.29 & 32.57 & $16: 46: 13$ & $17 / 06 / 1995$ \\
4.1 & 45 & 49.4 & 38.6 & $16: 45: 11$ & $06 / 07 / 1995$ \\
4.9 & 63 & 49.46 & 37.07 & $06: 56: 37$ & $15 / 10 / 1995$ \\
3.9 & 10 & 49.27 & 38.98 & $23: 23: 47$ & $04 / 11 / 1995$ \\
\hline
\end{tabular}


TABLE 6. Properties of earthquakes created in Central Alborz and Rudbar zones in 2000

\begin{tabular}{lccccc}
\hline Magnitude & Depth & \multicolumn{5}{c}{ Longitude Latitude } & Occurrence & Time & Date \\
\hline 3.5 & 114 & 45.92 & 34.3 & $12: 26: 50$ & $15 / 03 / 2000$ \\
4.2 & 33 & 48.17 & 36.96 & $3: 42: 40$ & $10 / 04 / 2000$ \\
4.1 & 40 & 49.57 & 37.02 & $20: 32: 51$ & $28 / 04 / 2000$ \\
3.9 & 33 & 48.05 & 37.95 & $5: 31: 17$ & $19 / 05 / 2000$ \\
\hline
\end{tabular}

TABLE 7. Properties of earthquakes created in Central Alborz and Rudbar zones in 2005 (from CMT in Catalog)

\begin{tabular}{lccccc}
\hline Magnitude & Depth & \multicolumn{5}{c}{ Longitude } & Latitude & Occurrence & Date \\
\hline 3.7 & 14 & 49.74 & 37.06 & $11: 31: 38$ & $01 / 01 / 2005$ \\
2.6 & 14 & 49.83 & 36.64 & $7: 02: 27$ & $02 / 01 / 2005$ \\
2.5 & 49.68 & 49.68 & 36.64 & $0: 0: 34$ & $09 / 03 / 2005$ \\
3.7 & 48.83 & 48.83 & 35.63 & $5: 41: 13$ & $10 / 03 / 2005$ \\
3.4 & 48.85 & 48.85 & 35.59 & $12: 3: 23$ & $08 / 04 / 2005$ \\
3.8 & 43 & 49.42 & 36.86 & $8: 44: 13$ & $14 / 04 / 2005$ \\
2.4 & 45 & 49.60 & 35.66 & $20: 39: 2$ & $17 / 05 / 2005$ \\
2.5 & 14 & 48.96 & 35.61 & $7: 48: 6$ & $03 / 06 / 2005$ \\
3.9 & 14.1 & 48.75 & 35.73 & $3: 50: 45$ & $24 / 07 / 2005$ \\
3 & 15 & 49.60 & 36.97 & $10: 42: 22$ & $24 / 08 / 2005$ \\
2.5 & 15.4 & 49.921 & 36.72 & $23: 37: 42$ & $02 / 11 / 2005$ \\
2.7 & 24.9 & 49.60 & 36.68 & $16: 20: 55$ & $29 / 11 / 2005$ \\
\hline & & & & &
\end{tabular}

TABLE 8. Numerical results of dynamic changes in Coulomb stress of Rudbar zone in 5-year intervals assuming the dip-slip fault

\begin{tabular}{cccc}
\hline Time & $\begin{array}{c}\text { Coulomb } \\
\text { stress }\end{array}$ & $\begin{array}{c}\text { Distance } \\
\text { from fault } \\
\text { center }(\mathbf{K m})\end{array}$ & $\begin{array}{c}\text { Intervals of } \\
\text { stress levels in } \\
\text { Bar }\end{array}$ \\
\hline & Increase & $70-100$ & $0.6-0.8$ \\
& & $100-130$ & $0.4-0.6$ \\
$\begin{array}{c}\text { During an } \\
\text { earthquake }\end{array}$ & & $0-75$ & $0-0.4$ \\
& Reduction & $75-130$ & $(-0.6)-(-0.8)$ \\
& & $130-300$ & $0-(-0.4)$ \\
\hline & & $0-60$ & $0.6-0.8$ \\
& Increase & $60-80$ & $0.4-0.6$ \\
& & $80-115$ & $0-0.4$ \\
& & $0-70$ & $(-0.6)-(-0.8)$ \\
& & $70-120$ & $(-0.4)-(-0.6)$ \\
& Reduction & $120-260$ & $0-(-0.4)$ \\
\hline
\end{tabular}

\begin{tabular}{|c|c|c|c|}
\hline \multirow{6}{*}{10 years later } & & $0-50$ & $0.6-0.8$ \\
\hline & Increase & $50-65$ & $0.4-0.6$ \\
\hline & & $65-100$ & $0-0.4$ \\
\hline & & $0-50$ & $(-0.6)-(-0.8)$ \\
\hline & Reduction & $50-85$ & $(-0.4)-(-0.6)$ \\
\hline & & $85-220$ & $0-(-0.4)$ \\
\hline \multirow{6}{*}{15 years later } & & $0-45$ & $0.6-0.8$ \\
\hline & Increase & $45-60$ & $0.4-0.6$ \\
\hline & & $60-80$ & $0-0.4$ \\
\hline & & $0-45$ & $(-0.6)-(-0.8)$ \\
\hline & Reduction & $45-80$ & $(-0.4)-(-0.6)$ \\
\hline & & $80-200$ & $0-(-0.4)$ \\
\hline \multirow{6}{*}{20 years later } & & $0-43$ & $0.6-0.8$ \\
\hline & Increase & $43-55$ & $0.4-0.6$ \\
\hline & & $55-70$ & $0-0.4$ \\
\hline & & $0-45$ & $(-0.6)-(-0.8)$ \\
\hline & Reduction & $45-70$ & $(-0.4)-(-0.6)$ \\
\hline & & $70-170$ & $0-(-0.4)$ \\
\hline \multirow{6}{*}{25 years later } & & $0-30$ & $0.6-0.8$ \\
\hline & Increase & $30-40$ & $0.4-0.6$ \\
\hline & & $40-80$ & $0-0.4$ \\
\hline & & $0-35$ & $(-0.6)-(-0.8)$ \\
\hline & Reduction & $35-50$ & $(-0.4)-(-0.6)$ \\
\hline & & $50-140$ & $0-(-0.4)$ \\
\hline \multirow{6}{*}{30 years later } & & $0-30$ & $0.6-0.8$ \\
\hline & Increase & $30-40$ & $0.4-0.8$ \\
\hline & & $40-80$ & $0-0.4$ \\
\hline & & $0-30$ & $(-0.6)-(-0.8)$ \\
\hline & Reduction & $30-40$ & $(-0.4)-(-0.6)$ \\
\hline & & $40-140$ & $0-(-0.4)$ \\
\hline
\end{tabular}

\section{CONCLUSIONS AND SUGGESTIONS}

Spatial and temporal changes in the crustal deformation process associated with the earthquakes depend on several parameters; doing the sensitivity analysis on these parameters is very important. Three different variables, namely, lithosphere thickness, asthenosphere viscosity and dip angle of fault, are some of these parameters [29-32].

The following results are obtained by doing the sensitivity analysis in co-seismic and post-seismic deformation due to dip-slip and strike-slip faulting:

The viscoelastic model sensitivity to input parameters is not correlated with the type of faulting. 
Co-seismic and post-seismic displacement analysis is highly dependent on the fault slip rate especially at the top of the rupture plane.

The co-seismic displacement analysis is highly dependent on the fault plane dip angle. The surface measurements in rupture plane are the most appropriate information for determining the probable value of the fault dip angle.

Co-seismic and post-seismic displacement analysis is a little dependent on the fault length.

Co-seismic and post-seismic displacement analysis is highly dependent on the fault width especially at the top of the rupture plane.

Co-seismic and post-seismic displacement analysis is highly dependent on the fault locking width especially at the top of the rupture plane and this dependence is higher for co-seismic displacement.

The co-seismic displacement analysis has no sensitivity to the viscosity coefficient of the viscoelastic half-space, but the deviations from the reference model are high at the top of the rupture plane by changing the viscosity and elastic layer thickness according to the deformation analysis after the earthquake. A little farther, where the horizontal displacement reaches the maximum level of another one, the viscosity and thickness of the elastic layer have again more impact than the dip angle of rupture level. Thus it is suggested to measure the viscosity in the zones with large postseismic displacement. Furthermore, this zone can provide information that is useful for determining the thickness of the elastic layer.

In a general state, the fault dip angle can be obtained using the post-seismic deformation information. The best place for finding the value of this parameter is where the direction of post-seismic displacement is changed.

The co-seismic displacement analysis shows no sensitivity to the density of elastic layer or viscoelastic half-space; in contrast, the post-seismic displacement analysis shows a little sensitivity to the density of elastic layer or viscoelastic half-space, thus it is no suggested determining the density of elastic layer or viscoelastic half-space by this model.

The occurrence of an earthquake can change the Coulomb stress distribution in the region and this leads to moving Coulomb stress changes, moving stress, even small, can lead to the rupture of surrounding faults even after a long time. This issue indicates the basic needs for modeling the Coulomb stress which refers to the future seismic hazards in the Iranian earthquake-prone plateau.

If the change in Coulomb stress is modeled considering the inter-seismic properties of faults for an inter-seismic period and calibrated according to the Coulomb stress changes due to the co-seismic and postseismic movements, the obtained model can be utilized as a tool for warning before an earthquake or for predicting the earthquakes. The accuracy of a model is highly dependent on the accuracy of its input parameters. The biggest problem in this regard is the lack of accurate data on active faults or very little accurate information in this regard.

According to various cases in selecting the reference fault geometry and physical properties of a reference environment, it is suggested choosing their value according to the physical and geometrical characteristics of a studied site and concerning the approximate and less-accurate values of non-geodetic methods for input parameters and their changes in the estimated error range of less-accurate methods.

The distribution of GPS stations is in a way that they are not so appropriate for determining the fault locking depth. To achieve better results especially in the case of locking depth, it is suggested utilizing the denser GPS networks especially in areas close to the faults.

\section{REFERENCES}

1. Sarlis, N. V., Skordas, E. S., and Varotsos, P. A., "Natural Time Analysis: Results Related to Two Earthquakes in Greece during 2019", Proceedings, Vol. 24, No. 1, (2019), 20. doi:10.3390/iecg2019-06194

2. Sharma, S., Venkateswarlu, H., and Hegde, A., "Application of Machine Learning Techniques for Predicting the Dynamic Response of Geogrid Reinforced Foundation Beds", Geotechnical and Geological Engineering, Vol. 37, No. 6, (2019), 4845-4864. doi:10.1007/s10706-019-00945-7

3. Sivandi-Pour, A., and Noroozinejad Farsangi, E., "Statistical Prediction of Probable Seismic Hazard Zonation of Iran Using Self-organized Artificial Intelligence Model", International Journal of Engineering, Transactions A: Basics, Vol. 32, No. 4, (2019), 467-473. doi:10.5829/ije.2019.32.04a.02

4. Sharma, N., Chakrabarti, A., Balas, V. E., and Martinovic, J., .Data Management, Analytics and Innovation, Vol. 1175, (2021) Singapore, Springer Singapore. doi:10.1007/978-981-15-5619-7

5. Cakir, Z., Barka, A. A., and Evren, E., "Coulomb Stress Interactions and the 1999 Marmara Earthquakes", Turkish Journal of Earth Sciences, Vol. 12, No. 1, (2003), 91-103

6. Ozturk, B. M., "Seismic drift response of building structures in seismically active and near -fault regions", Ph.D. Dissertations, Purdue University, (2003)

7. King, G. C., Stein, R. S., and Lin, J., "Some characteristic features of the Anatolian fault zone", Bulletin of the Seismological Society of America, Vol. 84, No. 3, (1994), 935953.

8. Freed, A. M., and Lin, J., "Delayed triggering of the 1999 Hector Mine earthquake by viscoelastic stress transfer", Nature, Vol. 411, No. 6834, (2001), 180-183. doi:10.1038/35075548

9. Wang, H., Liu, J., Shi, Y. L., Zhang, H., and Zhang, G. M., "Dynamic simulation of interactions between major earthquakes on the Xianshuihe fault zone", Science in China, Series D: Earth Sciences, Vol. 51, No. 10, (2008), 1388-1400. doi:10.1007/s11430-008-0110-8

10. Paolucci, R., Mazzieri, I., Piunno, G., Smerzini, C., Vanini, M., and Özcebe, A. G., "Earthquake ground motion modeling of induced seismicity in the Groningen gas field", Earthquake Engineering \& Structural Dynamics, Vol. 50, No. 1, (2021), 


\section{5-154. doi:10.1002/eqe.3367}

11. Al-Najjar, H. A. H., Kalantar, B., Pradhan, B., and Saeidi, V., "Conditioning factor determination for mapping and prediction of landslide susceptibility using machine learning algorithms", Earth Resources and Environmental Remote Sensing/GIS Applications X, Vol. 11156, (2019), 19. doi:10.1117/12.2532687

12. Galkina, A., and Grafeeva, N., "Machine learning methods for earthquake prediction: a Survey: A survey", Proceedings of the FourthConference on Software Engineering and Information Management (SEIM 2019), (2019), 25-32, RWTH Aahen University, 25-32

13. Zhou, Z., Lin, Y., Zhang, Z., Wu, Y., and Johnson, P., "Earthquake detection in 1D time-series data with feature selection and dictionary learning", Seismological Research Letters, Vol. 90, No. 2 A, (2019), 563-572. doi:10.1785/0220180315

14. Vasti, M., and Dev, A., "Classification and analysis of realworld earthquake data using various machine learning algorithms", Lecture Notes in Electrical Engineering, Vol. 612, (2020), 1-14. doi:10.1007/978-981-15-0372-6_1

15. Hossain, M. S., Al Hasan, A., Guha, S., and Andersson, K., "A belief rule based expert system to predict earthquake under uncertainty", Journal of Wireless Mobile Networks, Ubiquitous Computing, and Dependable Applications, Vol. 9, No. 2, (2018), 26-41. doi:10.22667/JOWUA.2018.06.30.026

16. Rundle, J. B., "Viscoelastic-gravitational deformation by a rectangular thrust fault in a layered Earth", Journal of Geophysical Research, Vol. 87, No. B9, (1982), 7787. doi:10.1029/JB087iB09p07787

17. Smith, B., and Sandwell, D., "Coulomb stress accumulation along the San Andreas Fault system", Journal of Geophysical Research: Solid Earth, Vol. 108, No. B6, (2003) doi:10.1029/2002jb002136

18. Thatcher, W., Matsuda, T., Kato, T., and Rundle, J. B., "Lithospheric loading by the 1896 Riku-u earthquake, northern Japan: implications for plate flexure and asthenospheric rheology.", Journal of Geophysical Research, Vol. 85, No. B11, (1980), 6429-6435. doi:10.1029/JB085iB11p06429

19. Deng, J., and Sykes, L. R., "Evolution of the stress field in southern California and triggering of moderate-size earthquakes: A 200-year perspective", Journal of Geophysical Research: Solid Earth, Vol. 102, No. B5, (1997), 9859-9886, doi:10.1029/96jb03897

20. Stein, S., and Wysession, M., An Introduction to Seismology, Earthquakes, and Earth Structure, (2009) John Wiley \& Sons.

21. Okada, Y., "Internal deformation due to shear and tensile faults in a half-space", Bulletin of the Seismological Society of America, Vol. 82, No. 2, (1992), 1018-1040.

22. Gitis, V. G., and Derendyaev, A. B., "Web-based GIS platform for automatic prediction of earthquakes", Lecture Notes in
Computer Science (Including Subseries Lecture Notes in Artificial Intelligence and Lecture Notes in Bioinformatics), Vol. 10962 LNCS, (2018), 268-283. doi:10.1007/978-3-31995168-3_18

23. Asim, K. M., Idris, A., Iqbal, T., and Martínez-Álvarez, F., "Earthquake prediction model using support vector regressor and hybrid neural networks", PLoS ONE, Vol. 13, No. 7, (2018), 122. doi:10.1371/journal.pone.0199004

24. Zhang, L., Si, L., Yang, H., Hu, Y., and Qiu, J., "Precursory Pattern Based Feature Extraction Techniques for Earthquake Prediction", IEEE Access, Vol. 7, (2019), 30991-31001. doi:10.1109/ACCESS.2019.2902224

25. Fernández, J., Yu, T. T., and Rundle, J. B., "Horizontal viscoelastic-gravitational displacement due to a rectangular dipping thrust fault in a layered Earth model", Journal of Geophysical Research B: Solid Earth, Vol. 101, No. 6, (1996), 13581-13594. doi:10.1029/96jb00525

26. Thatcher, W., and Rundle, J. B., "A viscoelastic coupling model for the cyclic deformation due to periodically repeated earthquakes at subduction zones.", Journal of Geophysical Research, Vol. 89, No. B9, (1984), 7631-7640. doi:10.1029/JB089iB09p07631

27. Wells, D. L., and Coppersmith, K. J., "New empirical relationships among magnitude, rupture length, rupture width, rupture area, and surface displacement", Bulletin of the Seismological Society of America, Vol. 84, No. 4, (1994), 974 1002

28. Okada, Y., "Surface deformation due to shear and tensile faults in a half-space", Bulletin of the Seismological Society of America, Vol. 75, No. 4, (1985), 1135-1154

29. Mignan, A., "A preliminary text classification of the precursory accelerating seismicity corpus: inference on some theoretical trends in earthquake predictability research from 1988 to 2018", Journal of Seismology, Vol. 23, No. 4, (2019), 771-785. doi:10.1007/s10950-019-09833-2

30. Razifard, M., Shoaei, G., and Zare, M., "Application of fuzzy logic in the preparation of hazard maps of landslides triggered by the twin Ahar-Varzeghan earthquakes (2012)", Bulletin of Engineering Geology and the Environment, Vol. 78, No. 1, (2019), 223-245. doi:10.1007/s10064-018-1235-4

31. Pandit, A., and Biswal, K. C., "Prediction of earthquake magnitude using adaptive neuro fuzzy inference system", Earth Science Informatics, Vol. 12, No. 4, (2019), 513-524. doi:10.1007/s12145-019-00397-w

32. Asim, K. M., Idris, A., Martinez-Alvarez, F., and Iqbal, T., "Short Term Earthquake Prediction in Hindukush Region Using Tree Based Ensemble Learning", Proceedings - 14th International Conference on Frontiers of Information Technology, FIT 2016, (2017), 365-370 doi:10.1109/FIT.2016.073 


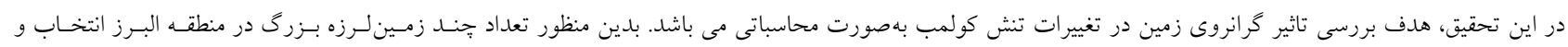

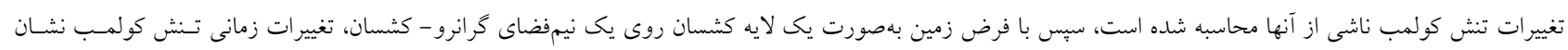

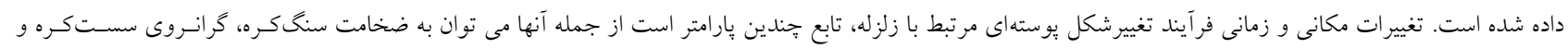

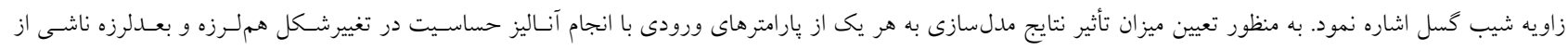

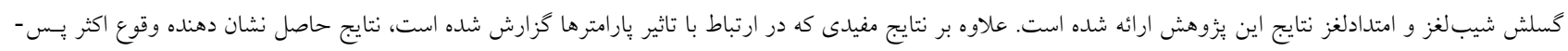

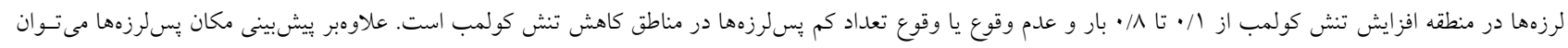

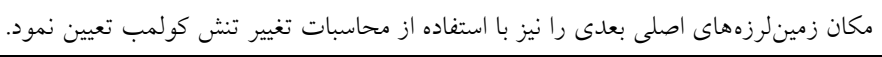

